\title{
The Geography and Demographics of Mortality from Alzheimer's disease
}

\section{Alexander Kholmanskiy}

Scientific Center BEMCOM, Moscow, Russia

Corresponding Author: Alexander Kholmanskiy, Scientific Center BEMCOM, Moscow, Russia.

E-mail: allexhol@ya.ru

Received date: November 11, 2019; Accepted date: November 29, 2019; Published date: December 06, 2019

Citation: Kholmanskiy A. (2019) The geography and demographics of mortality from Alzheimer's disease. J. Neuroscience and Neurological Surgery. 5(1); DOI:10.31579/2578-8868 /101

Copyright: (c) 2019 Alexander Kholmanskiy. This is an open-access article distributed under the terms of The Creative Commons Attribution License, which permits unrestricted use, distribution, and reproduction in any medium, provided the original author and source are credited.

\section{Abstract}

Study nature of epidemiological risk factors and patterns of distribution of mortality from Alzheimer's (MA) in 160 countries. An exponential Malthus model was used to construct adequate approximations of statistical data. Proportionality of average lifetime after 55 years $(\Delta t)$ to education index $(\Psi)$ was established. Ranking of countries by increasing value of $\Psi \Delta \mathrm{t}$ showed that MA depends exponentially on $\Psi \Delta \mathrm{t}$ and all countries can be divided into three groups in accordance with level of their economic development. In series of countries of low, medium and highly developed, their average values of MA increase exponentially. Growth of MA in developed countries in post-industrial epoch was explained by emergence of a new risk factor Alzheimer's of a mental nature. A mismatch of complexity or, on contrary, primitiveness of profession with level of mental development of worker, provokes development of chronic stress in him, fraught with pathologies of cognitive function metabolism in elderly. The geography of Alzheimer's disease was explained by the dependence of the human mentality on latitudinal climate change and on the chiral factor of a solar nature acting at night on a sleeping person.

Key words: mortality; alzheimer's; education; life expectancy; mentality; level of development

\section{Introduction}

Alzheimer's disease (AD) is the most common form of senile dementia in developed countries [1-3]. AD is considered a multifactorial disease and mutations of certain genes, the mechanism of which is not known, have a leading role in its development [4]. The epidemiological risk factors for the development of $\mathrm{AD}$ include age, genetic predisposition, cerebrovascular syndrome, diabetes mellitus $[5,6]$. The pathogenesis of $\mathrm{AD}$ begins to progress after 55-60 years, when the reproductive component of the hormonal background of brain metabolism weakens, controlled by the epiphysis and pituitary gland. In the same period, defective genes are activated and the protein metabolism of cerebral tissues is disturbed, leading to accumulation of amyloid and tau protein inside cells in the parenchyma and blood vessels of the brain. The deterioration of the rheological parameters of the brain's fluid systems leads to tissue hypoxia and the accumulation of chiral glucose in the blood, which leads to a decrease in the brain's energy potential and the kinetics of metabolic processes. Despite the enormous amount of empirical knowledge about $\mathrm{AD}$, the physicochemical nature and molecular mechanisms of the action of external and internal factors responsible for the etiology and pathogenesis of $\mathrm{AD}$ have not yet been established [2]. The absence of these data does not allow to purposefully develop effective and fairly harmless drugs for the prevention and treatment of $\mathrm{AD}$ and dementia [3].

It should be noted that the reliability of the patterns of global epidemiology of $\mathrm{AD}$ is determined by the adequacy of statistical data on the prevalence and mortality of AD per 100 thousand population (MA) in different countries. Auctores Publishing -Volume 5(2)-101 www.auctoresonline.org Page - 1
Currently, the most accurate are the results of a systematic study of the global regional and national burden of Alzheimer's disease and other dementias for 2016, which takes into account the analysis of the burden of these diseases for 1990-2016 [1]. The scientific inadequacy of statistical data may lead to erroneous results in studies of the nature of the epidemiological risks of $\mathrm{AD}$ for a particular region or country. For example, in work [7] it was not possible to establish climatic and ecological justifications for the leadership of Finland in the global MA rating given on the website [8] (Figure 1b). However, according to [1], MA for Finland has a different meaning, which is close to MA for Greece, Spain and significantly less than for Italy and Japan (Figure 1a).

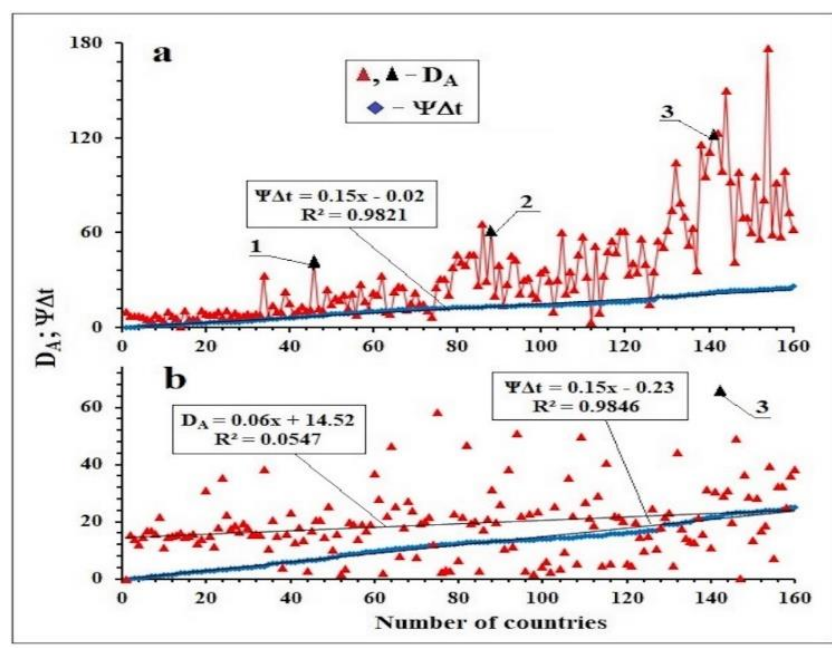

Figure 1: Country rankings and DA values by increasing $\Psi \Delta t$ ( $\Psi$ is the education index, $\Delta \mathrm{t}$ is the average lifetime after 55 years). The sequence 
dfas

numbers of countries in the Table. Points (1) and (2) - DA for China and India are not considered rural population, point (3) refers to Finland. Baseline data (a) from [1], (b) from [8].

Thus, the MA analysis carried out in [7] confirms that Finland has no pronounced regional and environmental specificity of the epidemiological risks of $\mathrm{AD}$. The inadequacy of the MA rating in [8] can also be judged by the MA value for Japan, which, it turns out, is an order of magnitude smaller than the MA figured in $[1,9]$.

Due to the global nature of heliobiology [10] and differences in the energy of sapientation in the countries above and below $\sim 40^{\circ}$ nl. [11] when studying the biophysical nature of the epidemiological risks of $\mathrm{AD}$, the role of solar factors must be taken into account. The human body and the brain as a whole is an open water-containing chiral biosystem capable of self-regulation in a narrow temperature range $(\mathrm{T}=309-310 \mathrm{~K})$ [12]. It is in this range that the anomalous properties of water ensure the stability of homeostasis and effective energy-informational exchange of the brain with the body and with the external environment.

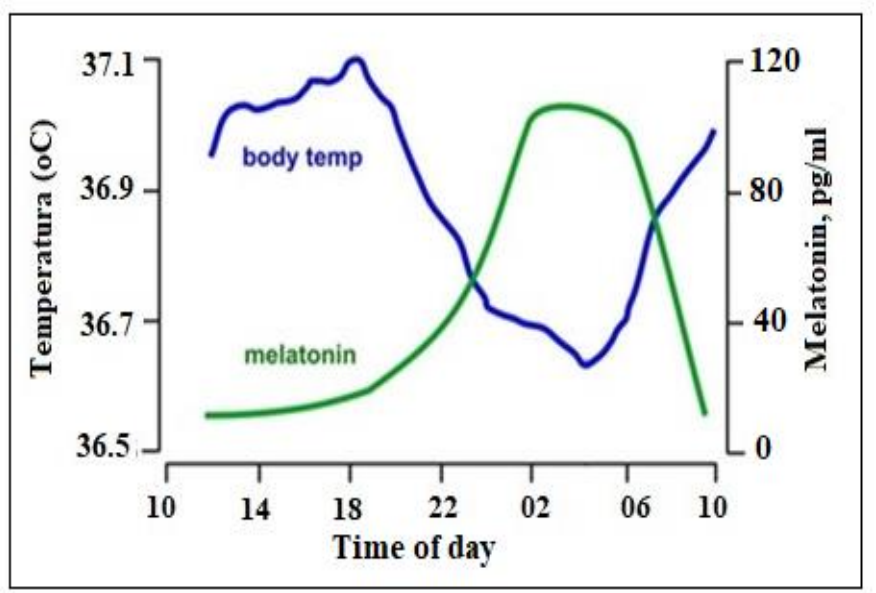

Figure 2: Daily variations in body temperature and melatonin levels in Human blood. Figure, from [14].

In $[11,12,13]$, it was suggested that the specificity of the night period of the circadian rhythm determines the chiral factor (CF) of a solar nature. In part, it is manifested in daily variations in plasma cortisol and melatonin levels [14]. Cortisol affects carbohydrate metabolism, increasing the concentration of glucose in the blood from 4 to 8 hours. Stress intensifies the production of cortisol, increasing the likelihood of diabetes. The maximum content of melatonin in the blood is observed in the middle of a normal night's sleep at 2-4 am (Figure 2).

It is possible that melatonin can inhibit the formation of amyloid plaques $[15,16]$. Violations of the night sleep mode lead to a decrease in the effectiveness of CFSN action and melatonin biosynthesis [17], the deficiency of which can provoke a disorganization of the metabolism at the neurohumoral level $[14,17]$. For example, people who systematically work at night increase the probability of the appearance of $\mathrm{AD}[15,16$, 18, 19], diabetes [20], and also cancer of various organs at women [21, 22] and men [23]. The positive and negative effects of CF and other biophysical factors on the brain or its individual organs can be carried out directly or through sensory systems outside the range of their normal sensitivity. In mice, for example, they found a decrease in the number of amyloid plaques when exposed to sound vibrations at a frequency of 40

$\mathrm{Hz}$ [24]. Since this frequency resonates with the $\gamma$-rhythm of the brain, it is believed [25] that in a person with AD such a sound can inhibit the formation of amyloids. Such effects are possible due to the acoustic properties of the fluid media of the brain [26] and the resonant connection of its $\gamma$-rhythm with the activity of the neurons of the auditory system [27].

Considering the key role of glucose and proteins in the metabolism of a sleeping man's brain, [12, 14] suggested that their biosynthesis and activity regulates $\mathrm{CF}$ and its intensity depends on geography and seasonality.

Thus, it can be considered that hereditary or acquired distortions of the physicochemical bonds of the body with the external environment are the basis of the molecular mechanisms of the etiology and pathogenesis of diseases such as $\mathrm{AD}$, oncology and diabetes. To substantiate this situation, in this paper, we studied the dependences of $\mathrm{AD}$ and MA on the characteristics of geography and climate, as well as on the level of education and average life expectancy of the population in 160 countries of the world. To identify the nature of the physical factor regulating the metabolism of the brain in the state of night sleep, we carry out daily and inter-seasonal monitoring of the optical activity of the dextran saline.

\section{Methods and materials}

The population loss $(\Delta N)$ from $A D$ in different countries for 2016 was taken from [1], and the total population of the countries (No) from [28]. MA per 100,000 population was calculated by the formula: MA = $(105 \Delta \mathrm{N}) /$ No. of the 190 countries in [1] left 160 countries for which there were values of the education index ( $\Psi)$ [29] and average life expectancy (tv) in which there were more than 55 years [30, 31]. Symptoms of AD begin to manifest themselves for men and women from $\sim 55$ years [1]. Taking this into account, we determined the temporal risk factor of AD $(\Delta \mathrm{t}$, years):

$$
\Delta \mathrm{t}=\mathrm{tv}-55
$$

Investigated a physiological solution of dextran with a molecular weight of from 30,000 to 40,000 ( $10 \mathrm{~g}$ of dextran and $0.9 \mathrm{~g}$ of NaCl per $100 \mathrm{ml}$ of water for injection). The angle of rotation of the polarization plane (o) of light (wavelength $589 \mathrm{~nm}$ ) was measured on a CM-3 circular polarimeter (measurement accuracy $\pm 0.02 \mathrm{o}$, cuvette $2 \mathrm{dm}$ long). The measurements were carried out at room $\mathrm{T}\left(24,5^{\circ} \mathrm{C} \pm 1{ }^{\circ} \mathrm{C}\right)$.

Statistics on mortality from $\mathrm{AD}$ in [1] are presented with a 95\% uncertainty interval (95\% UI). For their processing and graphing used the program Microsoft Office Excel 2010. 
dfas

Results

The value of $\Delta t$ is linearly dependent on $\Psi$ (Figure $3 a$ ), and a decrease in also the steady increase in $\mathrm{tv}$ with the development of countries $\Psi \Delta \mathrm{t}$ can be considered a demographic parameter characterizing the contribution of the population over 55 years old to the country's intellectual potential. The ranking of MA and countries with tv $>55$ years, by increasing values of $\Psi \Delta \mathrm{t}$ is presented in the Table and illustrated in Figure 1. It contains points 1) and 2) the values of MA for China and India, calculated without taking into account the share of rural (illiterate) population which for these countries amounted to $0.73 \mathrm{No}[32]$ and $0.43 \mathrm{No}$, respectively. the statistically average tv value due to MA is insignificant. Considering

The cognitive abilities of a person mainly suffer from $\mathrm{AD}$, which to a certain extent characterizes the value of $\Psi$, as well as the interval $\Delta t$, an increase in which leads to an increase in MA [9]. The population mortality dynamics from AD is subject to the Malthus exponential model and can be formally described by the equation [11]:

$$
\mathrm{MA}=(105 \Delta \mathrm{N}) / \mathrm{No}=\mathrm{k} \Psi \Delta \mathrm{t},
$$

here $\mathrm{k}$ is a constant (year-1).

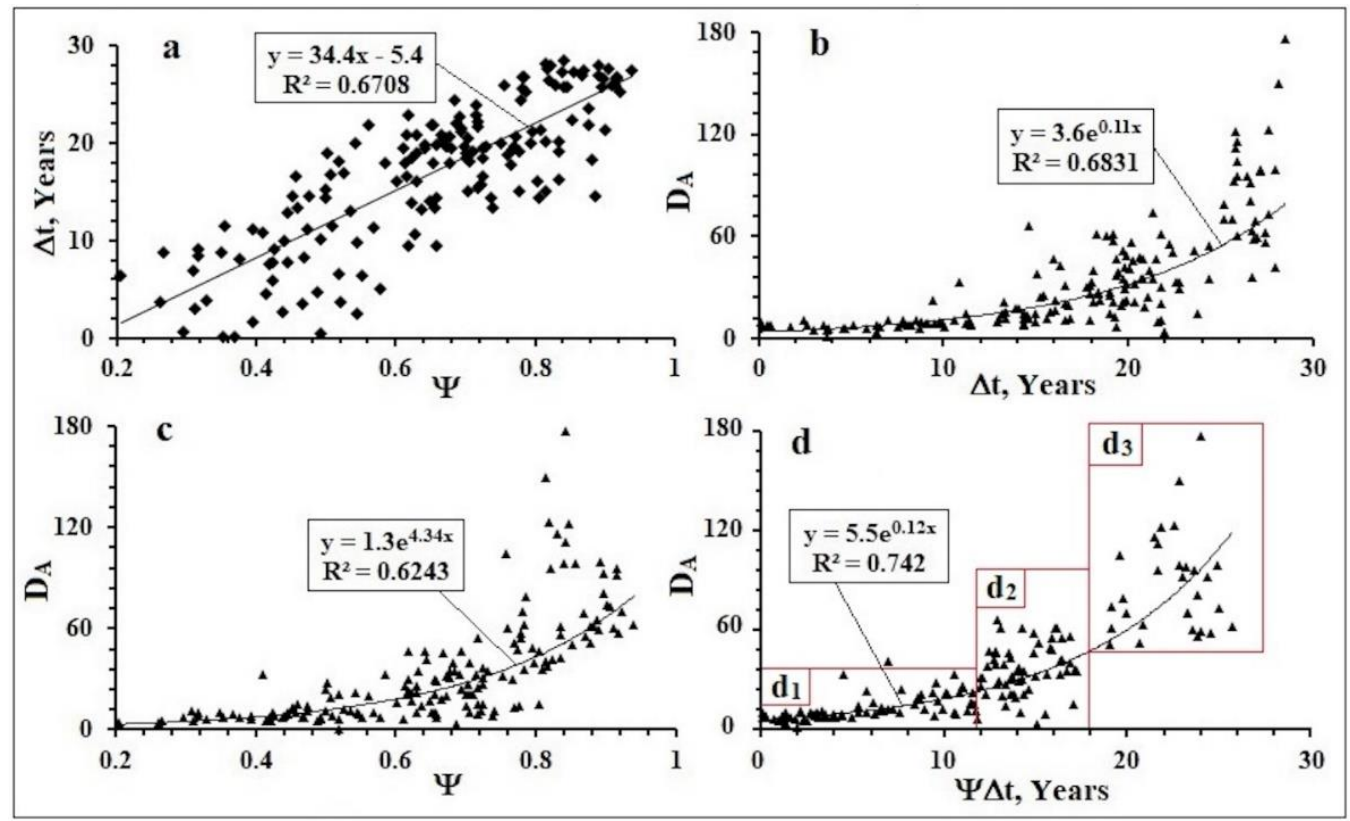

Figure 3: The dependence of the average lifetime after 55 years $(\Delta t)$ on the education index $(\Psi)$ for different countries (a) and exponential approximations of dependencies of the mortality rate $\left(\mathrm{M}_{\mathrm{A}}\right)$ for different countries on $\Delta \mathrm{t}(\mathrm{b})$, (c) and $\Psi \Delta \mathrm{t}(\mathrm{d})$. The rectangles are the countries that are intellectually and economically underdeveloped $\left(d_{1}\right)$, moderately developed $\left(d_{2}\right)$ and highly developed $\left(d_{3}\right)$. Baseline data for countries from [1].

From (1) it follows that MA will be proportional to the exponential $\exp (\mathrm{k} \Psi \Delta \mathrm{t})$. Figure 3 shows that the dependences of MA on $\Psi, \Delta \mathrm{t}$ and $\Psi \Delta \mathrm{t}$ are well approximated by the exponents, and the coefficient of confidence of the approximation (R2) has the greatest value with the exponent $\Psi \Delta \mathrm{t}$. The corresponding exponents are applicable for approximations of dependences of the prevalence of $\mathrm{AD}$ and MA on the age categories of patients in different countries $[1,4,9]$. 


\begin{tabular}{|c|c|c|c|c|c|c|c|c|c|c|c|}
\hline № & Country & $\Psi \Delta t$ & $\mathbf{D}_{\mathbf{A}}$ & № & Country & $\Psi \Delta t$ & $\mathbf{D}_{\mathbf{A}}$ & № & Country & $\Psi \Delta t$ & $\mathbf{D}_{\mathbf{A}}$ \\
\hline 1 & Mozambique & 0.04 & 9.67 & 55 & Honduras & 9.4 & 21.5 & 109 & Bosnia Herzeg. & 14.9 & 46.2 \\
\hline 2 & Guinea-Bissau & 0.1 & 7.04 & 56 & Tajikistan & 9.5 & 7.8 & 110 & Bulgaria & 14.9 & 57.5 \\
\hline 3 & South Sudan & 0.2 & 7.41 & 57 & Morocco & 9.6 & 27.5 & 111 & Sri Lanka & 15 & 31.9 \\
\hline 4 & Cameroon & 0.2 & 7.57 & 58 & Egypt & 9.7 & 16.6 & 112 & UAE & 15.1 & 3.4 \\
\hline 5 & Burundi & 0.7 & 6.32 & 59 & Uzbekistan & 9.9 & 11.6 & 113 & Romania & 15.1 & 51.5 \\
\hline 6 & Mali & 0.9 & 5.10 & 60 & Suriname & 10.1 & 22.1 & 114 & Bahrain & 15.5 & 9.1 \\
\hline 7 & Burkina Faso & 1 & 4.79 & 61 & Libya & 10.2 & 20.7 & 115 & Panama & 15.6 & 32.6 \\
\hline 8 & Equatorial Guinea & 1.1 & 7.61 & 62 & Salvador & 10.5 & 32.6 & 116 & Georgia & 15.8 & 48.4 \\
\hline 9 & Guinea & 1.3 & 5.91 & 63 & Belize & 10.6 & 10.0 & 117 & Uruguay & 15.9 & 54.9 \\
\hline 10 & Niger & 1.3 & 4.19 & 64 & Mongolia & 10.6 & 8.7 & 118 & Barbados & 15.9 & 47.7 \\
\hline 11 & Zimbabwe & 1.4 & 10.23 & 65 & Nicaragua & 10.8 & 22.4 & 119 & Latvia & 16 & 61.0 \\
\hline 12 & Uganda & 1.6 & 7.26 & 66 & Paraguay & 11 & 26.0 & 120 & Lithuania & 16.1 & 61.2 \\
\hline 13 & Benin & 1.9 & 5.84 & 67 & Trinidad \& & 11 & 25.2 & 121 & Albania & 16.3 & 33.1 \\
\hline 14 & Congo & 1.9 & 0.70 & 68 & Kyrgyzstan & 11.2 & 11.3 & 122 & Cuba & 16.4 & 40.9 \\
\hline 15 & Djibouti & 2.2 & 10.89 & 69 & Azerbaijan & 11.4 & 15.5 & 123 & Slovakia & 16.4 & 41.6 \\
\hline 16 & Togo & 2.3 & 5.26 & 70 & Dominic. & 11.5 & 22.2 & 124 & Singapore & 16.4 & 34.9 \\
\hline 17 & Eritrea & 2.3 & 5.53 & 71 & Kazakhstan & 11.6 & 14.7 & 125 & Costa Rica & 16.7 & 56.1 \\
\hline 18 & Liberia & 2.5 & 5.40 & 72 & Fiji & 11.7 & 14.6 & 126 & Hungary & 16.8 & 39.9 \\
\hline 19 & Sudan & 2.7 & 10.52 & 73 & Palestine & 11.7 & 10.6 & 127 & Montenegro & 16.9 & 14.8 \\
\hline 20 & Ethiopia & 2.9 & 8.71 & 74 & Kuwait & 11.9 & 6.3 & 128 & Brunei & 17 & 35.4 \\
\hline 21 & Zambia & 2.9 & 7.67 & 75 & Colombia & 12 & 25.5 & 129 & Argentina & 17.2 & 54.7 \\
\hline 22 & Mauritania & 3.1 & 7.83 & 76 & Moldova & 12 & 30.9 & 130 & Chile & 17.2 & 35.8 \\
\hline 23 & Yemen & 3.1 & 9.81 & 77 & Saint Lucia & 12.1 & 30.6 & 131 & Poland & 19.1 & 50.6 \\
\hline 24 & Papua New & 3.2 & 6.87 & 78 & Maldives & 12.2 & 20.5 & 132 & Estonia & 19.1 & 61.3 \\
\hline 25 & Haiti & 3.3 & 10.76 & 79 & Russia & 12.3 & 37.9 & 133 & USA & 19.2 & 74.1 \\
\hline 26 & Kenya & 3.4 & 6.78 & 80 & Thailand & 12.4 & 46.4 & 134 & Portugal & 19.6 & 104.3 \\
\hline 27 & Malawi & 3.5 & 8.96 & 81 & Tunisia & 12.7 & 41.5 & 135 & Cyprus & 19.8 & 79.1 \\
\hline 28 & Ghana & 3.5 & 7.36 & 82 & Seychelles & 12.8 & 39.4 & 136 & Malta & 20 & 70.0 \\
\hline 29 & Comoros & 3.9 & 7.19 & 83 & Vietnam & 12.8 & 46.3 & 137 & Czech Republic & 20.7 & 51.9 \\
\hline 30 & Rwanda & 3.9 & 8.69 & 84 & Ukraine & 12.8 & 46.4 & 138 & Luxembourg & 20.9 & 62.7 \\
\hline 31 & Senegal & 4.1 & 7.27 & 85 & Samoa & 12.9 & 26.6 & 139 & Greece & 21.5 & 115.9 \\
\hline 32 & Tanzania & 4.4 & 8.57 & 86 & Slovenia & 12.9 & 65.7 & 140 & Austria & 21.6 & 95.5 \\
\hline 33 & Pakistan & 4.4 & 8.25 & 87 & Algeria & 13 & 29.4 & 141 & Belgium & 21.7 & 111.5 \\
\hline 34 & Myanmar & 4.5 & 32.85 & 88 & China & 13.1 & 61.0 & 142 & Finland & 21.9 & 121.6 \\
\hline 35 & Madagascar & 5 & 6.62 & 89 & Peru & 13.2 & 19.7 & 143 & Spain & 22.6 & 123.0 \\
\hline 36 & Laos & 5.3 & 14.20 & 90 & Brazil & 13.3 & 39.2 & 144 & France & 22.8 & 98.9 \\
\hline 37 & Namibia & 5.4 & 9.72 & 91 & Jordan & 13.3 & 14.3 & 145 & Italy & 22.9 & 149.9 \\
\hline 38 & Solomon Islands & 5.7 & 9.81 & 92 & Grenada & 13.3 & 27.1 & 146 & UK & 23 & 92.3 \\
\hline 39 & Gabon & 5.8 & 22.58 & 93 & Turkey & 13.6 & 45.5 & 147 & Sweden & 23.3 & 98.2 \\
\hline 40 & Cambodia & 6.2 & 15.61 & 94 & Belarus & 13.6 & 42.8 & 148 & Denmark & 23.3 & 69.9 \\
\hline 41 & Botswana & 6.3 & 8.83 & 95 & Venezuela & 13.6 & 21.3 & 149 & South Korea & 23.3 & 69.5 \\
\hline 42 & Guyana & 6.5 & 10.71 & 96 & Tonga & 13.6 & 30.0 & 150 & Ireland & 23.6 & 60.2 \\
\hline 43 & Bhutan & 6.6 & 13.00 & 97 & Macedonia & 13.7 & 31.6 & 151 & Germany & 23.7 & 95.5 \\
\hline 44 & Turkmenistan & 6.7 & 10.65 & 98 & Malaysia & 13.8 & 21.3 & 152 & Israel & 23.8 & 55.9 \\
\hline 45 & Nepal & 6.9 & 11.60 & 99 & Ecuador & 13.9 & 18.6 & 153 & Netherlands & 23.9 & 80.7 \\
\hline 46 & India & 7 & 41.00 & 100 & Jamaica & 14 & 34.9 & 154 & Japan & 24 & 176.7 \\
\hline 47 & Iraq & 7.2 & 11.74 & 101 & Mauritius & 14.1 & 36.6 & 155 & Canada & 24 & 58.9 \\
\hline 48 & Bangladesh & 7.6 & 10.31 & 102 & Dominica & 14.1 & 29.5 & 156 & Norway & 24.4 & 91.6 \\
\hline 49 & North Korea & 7.7 & 24.12 & 103 & Oman & 14.2 & 10.2 & 157 & New Zealand & 24.6 & 57.9 \\
\hline 50 & Philippines & 8.4 & 14.56 & 104 & Mexico & 14.3 & 30.4 & 158 & Switzerland & 24.9 & 99.1 \\
\hline 51 & Guatemala & 8.5 & 18.87 & 105 & Serbia & 14.3 & 60.5 & 159 & Iceland & 25 & 72.7 \\
\hline 52 & Indonesia & 8.6 & 17.62 & 106 & Iran & 14.4 & 21.2 & 160 & Australia & 25.7 & 62.4 \\
\hline 53 & Bolivia & 8.7 & 20.80 & 107 & Armenia & 14.4 & 35.3 & & & & \\
\hline 54 & Vanuatu & 8.9 & 11.89 & 108 & $\begin{array}{l}\text { Antigua and } \\
\text { Barbuda }\end{array}$ & 14.6 & 24.3 & & & & \\
\hline
\end{tabular}

Table 1: Intelligence parameter ( $\Psi \Delta \mathrm{t}$, years $)$ and mortality rate $\left(\mathrm{M}_{\mathrm{A}}\right.$, patients per 100000$)$ 


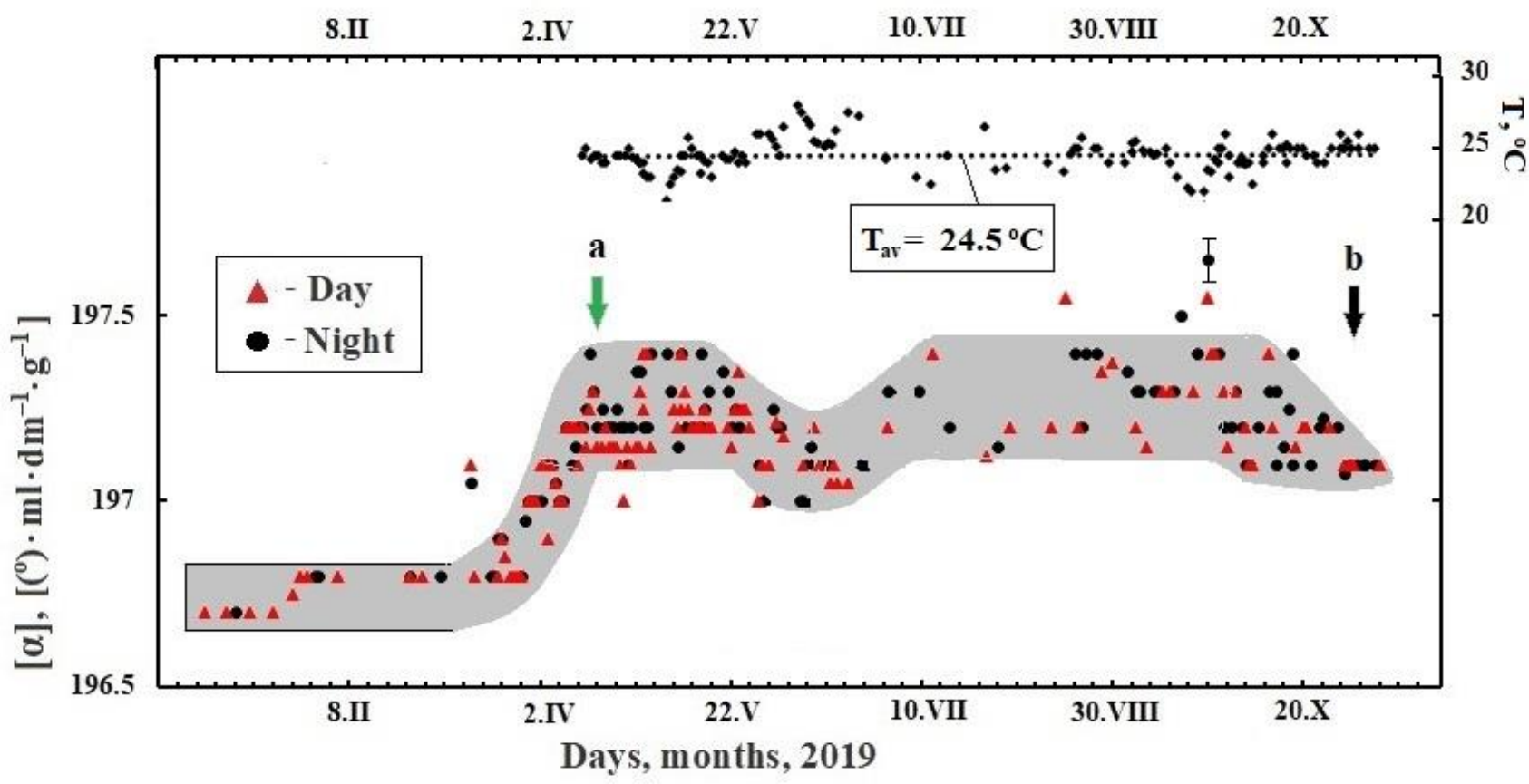

Figure 4: Monitoring temperature and optical activity (specific rotation) $[\alpha]$ of an aqueous solution of dextran, $\mathrm{T}_{\mathrm{av}}-$ average temperature. Arrow a - the appearance of greenery on birches, arrow $b-$ the first snow. The fluctuations ranges of [ $\alpha]$ [33] are tinted.

The inter-seasonal monitoring of temperature $(\mathrm{T}$ oC) and specific rotation $[\alpha]$ (optical activity) of the dextran aqueous solution are shown in Figure 4. Arrows in Figure 4 marks the appearance of greenery on birches (a) and first snow (b). Estimation of the activation energy (EA), obtained from the Arrhenius approximation of the dependence of $[\alpha]$ on $\mathrm{T}$ for a dextran solution, gave a value of $0.38 \mathrm{~kJ} / \mathrm{mol}$, close to EA for physiological glucose solution - $0.33 \mathrm{~kJ} / \mathrm{mol}$ [33]. A slight decrease in $[\alpha]$ dextran is observed with an abnormal increase in $\mathrm{T}$ in the first half of June 2019, in other periods the changes in $[\alpha]$ correlated with the seasonal dependence of the activity of plant metabolism.

\section{Discussion}

From data analysis of the Tables and approximations of the distribution by country of the global mortality rate from $\mathrm{AD}(\mathrm{MA})$ and intellectual potential $(\Psi \Delta \mathrm{t})$ (Figure 1, Figure 3), it follows that both demographic characteristics depend on the level of economic development of countries, and DA exponentially depends on $\Psi \Delta \mathrm{t}$. The ranking of countries on the rise $\Psi \Delta$ t led to the division of countries according to the level of intellectual and economic development into three groups, which in coordinates MA and $\Psi \Delta \mathrm{t}$ in Figure $2 \mathrm{~d}$ form three zones, highlighted by rectangles $\mathrm{d} 1$ (1-75), $\mathrm{d} 2$ (76-131) and $\mathrm{d} 3$ (132 -160), in brackets the numbers of countries in the Table. These zones correspond to the division of countries of the world according to economic criteria for weak (d1), medium (d2) and highly developed (d3). There are no sharp boundaries on the $\Psi \Delta$ t coordinate between the $\mathrm{d} 1$ and $\mathrm{d} 2$ countries of the groups, but they have significantly less intellectual potential and MA than those of the $\mathrm{d} 3$ countries. The average values of $\Psi \Delta \mathrm{t}$ in $\mathrm{d} 1, \mathrm{~d} 2$ and $\mathrm{d} 3$ groups grow in an arithmetic progression - 5.9; 14.4; 22.5 years, and MA in geometrical - $12.7 ; 36.5 ; 87.1$ per 100,000 population.

Large values of MA in the d3 group can be associated with the civilizational, mental risk factor of $\mathrm{AD}$, which is based on discrepancies between the professions of the post-industrial epoch and the level of mental development of workers. For some professions, a person may not have the necessary education and natural abilities, and the performance of others, on the contrary, suppresses his mentality. Both situations are fraught with chronic stress, which leads to the degradation of cognitive functions and harmful changes in the brain $[34,35]$. Such changes can easily occur in the brain of a child, which is immature up to 10-12 years old [36], if scientifically unfounded technologies are used in the process of learning. For example, in Japan children are required to learn the left hemisphere syllable alphabet in combination with the right-hemispheric hieroglyphics before school and in primary school [37]. At the same time, inevitable distortions of the natural functional specialization of the brain hemispheres can subsequently provoke and strengthen the effects of the mental risk factor of $\mathrm{AD}$, which ultimately leads to an increase in MA in Japan to a record value in the $\mathrm{d} 3$ group. For comparison, in China, teaching hieroglyphic literacy is not as accelerated as in Japan and, accordingly, MA in China is three times less than in Japan.

The high efficiency of the sapientation process of countries of the $\mathrm{d} 3$ group, located, as a rule, in the zone above $35-40 \mathrm{o} \mathrm{s}$. sh. in [11], they were associated with a low level of their insolation and average annual temperature, as well as with a high efficiency of the effect of CF during the night and early morning $[12,13,14,38,39,40]$. In d1 countries, the relationship between these climatic and solar factors is reversed, which explains the low $\Psi \Delta \mathrm{t}$ and MA values in these countries compared with the $\mathrm{d} 3$ group countries. The physical nature of $\mathrm{CF}$ is not known, a priori endows it with helicity and high penetrating power, which is not inherent in the corpuscular and electromagnetic radiation of the Sun. In principle, solar neutrinos possess such properties, however, its physical nature still remains an unsolved problem of the physics of elementary particles [12, 41]. It is believed [38] that CF activates the processes of self-organization in water-containing cooperative biosystems containing homogeneous chiral molecules or molecular complexes. For the intensity of the solar neutrino flux of the beryllium cycle, an annual rhythm was revealed [42], due to the difference in distance between the Sun and the Earth in winter and summer.

The increase in $[\alpha]$ value of dextran solution after March 22 (Figure 4) correlates with the process of spring awakening of plants and confirms the hypothesis of the participation of $\mathrm{CF}$ in the metabolism of living organisms. The effect of $\mathrm{CF}$ can be explained by numerous observations 
dfas

of the anomalous productivity of living organisms and, above all, living in the aquatic environment (Figure 5) [10,40]. Correlations of diurnal changes $[\alpha][14,33]$ and blood concentrations of cortisol, sugar and melatonin (Figure 2) indicate an increase in CF activity at night. In addition to the time factor and violations of the night sleep mode, the activity of the CF will be influenced by geographical parameters (latitude, composition of the lithosphere, hydrosphere).

Cooperative effects in biosystems, and hence their sensitivity to $\mathrm{CF}$, depend significantly on the $\mathrm{T}$ of the human body and brain (Figure 2). An important role in the cognitive functions of the brain is played by metabolic processes in the structures of the frontal-temporal lobes [36]. The kinetics of these processes depends on stationary $\mathrm{T}$ [43], the value of which is determined by the intensity of metabolic processes and the rate of removal of excess heat from the brain by venous blood and the bones of the skull. The latter process effectively proceeds through the bones of the inner walls of the paranasal sinuses of the skull, since they are ventilated with inhaled air having a $\mathrm{T}$ external environment.

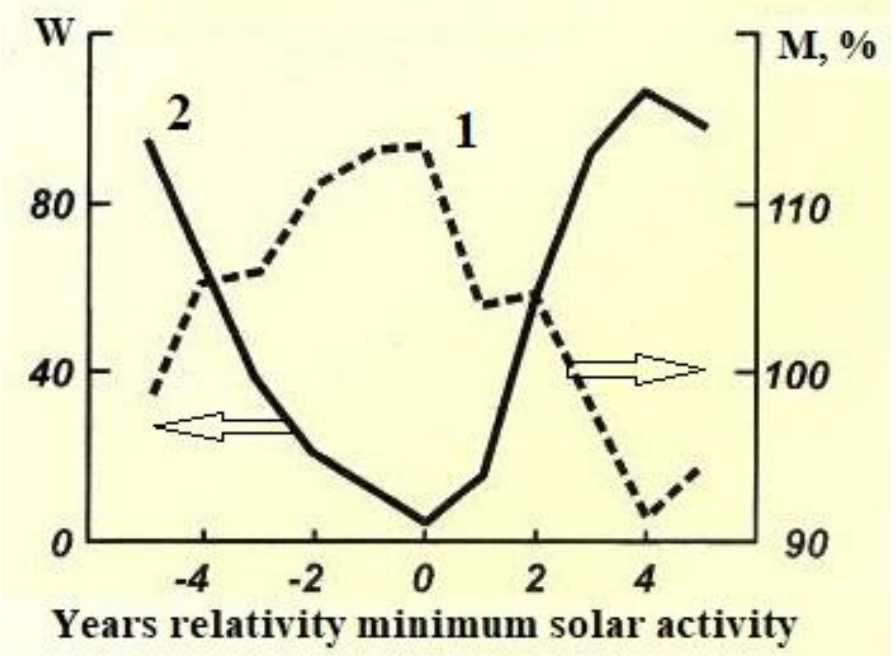

Figure 5: Grayan's mussel growth (M) in the northwestern part of the Sea of Japan (1), W is the number of sunspots during the minimum years of its activity (W) from [10].

With its decrease at night and slowing down of metabolic processes in sleep, the brain's $\mathrm{T}$ decreases by $\sim 1{ }^{\circ} \mathrm{C}$ [43]. It follows that the stationary $\mathrm{T}$ of the frontal lobes of the aborigines of countries of the $\mathrm{d} 1$ group may be higher by tenths of a degree [43] than among the aborigines of the countries of the $\mathrm{d} 3$ group. This difference in $\mathrm{T}$ will affect the metabolism of cognitive functions and the quantum effects in the fluidic media of the brain, ensuring its response to the effects of CF [12, 33, 43]. Normally and pathologies, brain fluid systems contain glucose, amino acids and amyloid protein precursors [44, 45, 46]. The effect of CF and a decrease in brain $\mathrm{T}$ during a night's sleep can trigger the association of glucose, amino acids [14, 46, 47] and the aggregation of precursor proteins into amyloid plaques and fibrils $[46,48]$. Changes in the balance of right-left amino acids in the fluid systems of the brain [49] under the influence of $\mathrm{CF}$ and temperature can lead to mutations of the genes responsible for the metabolism of amyloid protein [4].

\section{Conclusion}

The demographic analysis of statistical data on mortality from $\mathrm{AD}$ showed that, in the post-industrial epoch, the inadequate realization of the human mentality in the process of professional activity becomes a significant epidemiological risk factor for AD. Herewith in developing countries a lack of competence prevails, and in highly developed countries, it may be supplemented by the suppression of the natural abilities of a person by work in the service sector. In both situations, the human psyche will be traumatized and irreversible deformations of the neurophysiology of cognitive functions will occur, which in old age can provoke the development of AD. This mechanism of action of the mental risk factor $\mathrm{AD}$ is confirmed by the exponential dependence of its distribution on the education index of countries The geography of the mortality rate from $\mathrm{AD}$ agrees well with the difference in the effectiveness of the chiral solar and temperature factors on the physiology of the cognitive abilities of the Aboriginal countries of the North and South.

\section{References}

1. GBD 2016 Dementia Collaborators, Global, regional, and national burden of Alzheimer's disease and other dementias, 1990-2016: a systematic analysis for the Global Burden of Disease Study 2016, The Lancet Neurology. 2019, 18(1). Pp.88-106

2. Zakharov V.V., Vakhnina N.V., Gromova D.O., Tarapovskaya A.A. Review of materials of the international conference on Alzheimer's disease, Washington, 18-23 of July, 2015, Neurological J. 2015; 20 (6): pp. 65-69.

3. Koberskaya NN. Current views of the risk factors, diagnosis, and therapy of Alzheimer's disease (according to the proceedings of the Alzheimer's Association International Conference, London, 2017). Neurology, neuropsychiatry, psychosomatics. 2017; 9(3): pp. 81-87.

4. Ertekin-Taner, N. Genetics of Alzheimer disease in the preand post-GWAS era. Alzheimer's Research \& Therapy. 2010. $2: 3$.

5. Xu, W., Ferrari, C., Wang, H.-X. Epidemiology of Alzheimer's Disease, Understanding Alzheimer's Disease, Inga Zerr, Intech Open, 2013,

6. Rizzi,L., Rosset,I., Roriz-Cruz, M. Global Epidemiology of Dementia: Alzheimer's and Vascular Types. Biomed Res Int. 2014; 2014: 908915.

7. Eiser, A.R. Why Does Finland Have the Highest Dementia Mortality Rate? Environmental Factors May Be Generalizable, Brain Research, 2017

8. World Health Rankings: Alzheimer's/dementia

9. Ono, K. et al. Apparent Increases in Age-Specific Morbidity and Mortality of Alzheimer's Disease in Japan. EC Neurology. 2019, 11.1, pp. 38-45.

10. Vladimirsky B.M., Temuryants N.A. The effect of solar activity on the biosphere-noosphere. Heliobiology from A.L. Chizhevsky to the present day. M. MNEPU, 2000, 374 p.

11. Kholmanskiy, A. S., Nurgaliev, I. S., Strebkov, D. S. Sapientation process energy. Economic strategy, 2018, 7, pp. 118-125.

12. Kholmanskiy, A. Dialectic of Homochirality. Preprints 2019, 2019060012

13. Kholmanskiy, A.S. Dependence of the resource of functional asymmetry of the brain on external conditions. The galactic factor of spiritual evolution. Asymmetry. 2009, 3 (1), pp. 5171. 
14. Kholmanskiy, A., Zaytseva, N. Chiral Factor of Circadian Rhythm of Human Physiology, Int. J. Res. Pharm. Biosci. 2018, 5(4) pp. 6-10. URL:

15. Shokri-Kojori, E. Wang, G.-L., Wiers,C.E. et al. $\beta$-Amyloid accumulation in the human brain after one night of sleep deprivation. PNAS, 2018, 115 (17), pp. 4483-4488

16. Beil, L. The brain may clean out Alzheimer's plaques during sleep. Science news, 2018, 194(2), p. 22

17. Blask, D.E., Dauchy, R.T., Sauer, L.A., et al. Light during darkness, melatonin suppression and cancer progression. Neuroendocrin. Let. 2002; 23(2), pp.52-56.

18. van Someren, E.J., Mirmiran, M., Swaab, D.F. Nonpharmacological treatment of sleep and wake disturbances in aging and Alzheimer's disease: chronobiological perspectives. Behavioural Brain Res. 1993. 57 (2): 235-253.

19. Omonigho, M. et al. Sleep, Cognitive impairment, and Alzheimer's disease: A Systematic Review and MetaAnalysis. Sleep. 2017, 40

20. Suwazono $\mathrm{Y}$ et al. Longitudinal study on the relationship between alternating shift work and the onset of diabetes mellitus in male Japanese workers. J. Occupational and Environmental Med. 2006; 48(5): pp. 455-461.

21. Xia, Y. et al. Night Shift Work Increases the Risks of Multiple Primary Cancers in Women: A Systematic Review and Meta-analysis of 61 Articles. Cancer Epidemiology, Biomarkers \& Prevention. 2018.

22. Jiao, L. et al. "Sleep duration and incidence of colorectal cancer in postmenopausal women." Br. J. Cancer. 2013. 108(1): pp. 213-221

23. Parent, M., El-Zein, M., Rousseau, M. et al. Night Work and the Risk of Cancer Among Men. Am. J. Epidemiology, 2012, 176(9), pp. 751-759

24. Ismail,R., Hansen, A.K., Parbo, P. et al. The Effect of $40-\mathrm{Hz}$ Light Therapy on Amyloid Load in Patients with Prodromal and Clinical Alzheimer's Disease. Int. J. Alzheimer's Disease, 2018, Article ID 6852303, 5 p.

25. Thomson, H. How flashing lights and pink noise might banish Alzheimer's, improve memory and more. Nature, 2018, 555, pp. 20-22

26. Kholmanskiy, A.S., Minakhin A.A. Phylogeny factors of posture and morphogenesis of the human brain. Sciences. 2012. 4, P. 1-8.

27. Kholmanskiy, A.S., Minakhin, A.A. Interconnection of electrical oscillations of the heart and brain. Bull. St.-P. State Univ. Med. 2018, 13(2) pp. 117-135.

28. The population of the countries of the world for 2016 .

29. Ranking of countries by level of education. Humanitarian encyclopedia: Research. Center for humanitarian technologies, 2019.

30. WHO. Life expectancy and Healthy life expectancy. Data by country.

31. Average life expectancy in Russia and the world in 2018. bslife.ru.
32. Chandra, V., Ganguli, M., Pandav, R. et al. Prevalence of Alzheimer's disease and other dementias in rural India: the Indo-US study. Neurology. 1998; 51: pp.1000-1008.

33. Kholmanskiy, A. Chirality anomalies of water solutions of saccharides. J. Mol. Liq 2016, 216, pp. 683-687.

34. Karp, A., Andel, R., Parker, M.G. et al. Mentally Stimulating Activities at Work During Midlife and Dementia Risk After Age 75: Follow-Up Study From the Kungsholmen Project. American J. Geriatric Psychiatry. 2009;17(3):227-236

35. Then, F.S. Aranda, M.P. Vega, W.A. How Your Work Can Reduce Your Dementia Risk. USC Edward R. Roybal Institute on Aging. 2017.

36. Bezrukikh, M.M., Sonkin, V.D., Farber, D.A. Developmental physiology: (Physiology of child development). 2003. M. Academy, 416 p. ISBN 5-7695-0581-8.

37. Ivanov, V. V. Selected works on semiotics and history of culture. 1999. Vol.1. M. 912 p. ISBN 5-7859-0073-4.

38. Kholmanskiy, A.S. Activation of biosystems by an external chiral factor and a decrease in temperature. Asymmetry. 2018, 12(3) pp. 64-77. URL:

39. Kholmanskiy, A.S. Chirality and quantum effects as factors of morphogenesis. Electron. Math. Med.-Biol. J. 2010. 9(4)

40. Chernoschekov K.A., Lepekhin A.V. Materialization of the ideas of A.L. Chizhevsky in epidemiology and microbiology. Tomsk: TSU, 1993. 273 p.

41. Giunti C., Studenikin A. Neutrino electromagnetic interactions: a window to new physics. Rev. Mod. Phys. 2015. 87.531.

42. M. Agostini et al. (Borexino Coll.), Seasonal Modulation of the 7Be Solar Neutrino Rate in

Borexino, Astropart.Phys. 2017, 92, pp. 21-29,

43. Wang, H., Wang, B., Normoyle, K.P. et al. Brain temperature and its fundamental properties: A review for clinical neuroscientists. Front. Neurosci., 2014. 8(307)

44. Weinstein, G., Maillard, P., Himali, J.J. et al. Glucose indices are associated with cognitive and structural brain measures in young adults. Neurology. 2015;84(23):2329-2337.

45. Fisher, G., Lorenzo, N., Abe, H. Free D- and L-amino acids in ventricular cerebrospinal fluid from Alzheimer and normal subjects. Amino Acids. 1998. 15(3): pp. 263-269

46. Yakhno, N. N. Dementia: a guide for doctors. 2010. M. 2010. 272 p. ISBN 5-98322-449-5

47. Weili Xu, W., Qiu, C., Gatz, M. et al. Mid- and Late-Life Diabetes in Relation to the Risk of Dementia. Diabetes, 2009, 58(1): pp. 71-77

48. Structure formation in chiral systems. Supramolecular strings. Ed. V.A. Tverdislov. M. 2016. 312 p. ISBN 978-5-8279-01372.

49. Chervyakov A.V. Violation of molecular asymmetry of amino acids (D L-enantiomers) during normal aging and neurodegenerative diseases. Asymmetry. 2010. 2. 